\title{
Coupled radiation and natural convection within an inclined sinusoidal solar collector heated from below
}

\author{
Djamel Sadaoui ${ }^{1}$, Adel Sahi $^{1, a}$, Abderrahmane Djerrada ${ }^{1}$ and Kacem Mansouri ${ }^{2}$ \\ 1 Laboratoire de Mécanique, Matériaux et Energétique (L2ME), Faculté de Technologie, Université A. Mira de Bejaia, \\ 06000 Bejaia, Algérie \\ 2 Laboratoire Energétique, Mécanique et Ingénieurie (LEMI), Université M. Bouguerra de Boumerdès, \\ 35000 Boumerdès, Algérie
}

Received 30 November 2014, Accepted 30 July 2015

\begin{abstract}
The main objective of this article is to study the effect of coupled mode free convection with surface radiation on the fluid flow behavior inside a tilted solar collector having a flat glass cover and a wavy bottom absorber. The cavity is subject to vertical gradient temperature while its top sidewalls remain thermally insulated. The dimensionless governing equations under Boussinesq approximation are coupled with a radiative model through the boundary conditions and solved by the Finite Volume Method. The numerical results are discussed in terms of streamlines, isotherms, convective and radiative Nusselt number along the cover plate for various aspect ratios, inclination angle, emissivity and Rayleigh number. These results highlighted the condition of the enclosure performance and revealed that the heat and fluid flow fields are affected by surface radiation and the above parameters. In the end, correlations for predicating the convection heat loss in term of averaged Nusselt numbers are developed in both pure free convection and coupled convection-surface radiation modes.
\end{abstract}

Key words: Free convection / surface radiation / tilted angle / sinusoidal surface / solar collector

\section{Introduction}

Convection heat transfer in enclosures has received considerable attention over the past few decades in view of the numerous potential applications. A literature survey related to this topic revealed that previous studies are substantially oriented toward describing the phenomenon of free convection in cavities with flat walled geometries. In this field, benchmark solutions of De Vahl Davis [1] and Le Quere [2] have been widely considered as a reference by many authors.

The interest has now shifted to complex enclosures with irregular surfaces. Therefore, wavy surfaces are suitable techniques to improve the thermal performance of heat transfer devices. Solar collectors, grain storage containers, industrial heat radiators and electronic cooling, are some applications where non-uniform surfaces are encountered to transfer heat. In thermal solar, the collectors are designed usually as shallow enclosures; their absorbers can be different geometry such as flat, wavy or corrugated. The main requirement of the solar collector is a large contact area between the absorbing surface and the working fluid. In this context, Adjlout et al. [3] reported

${ }^{a}$ Corresponding author: sahi.adel@hotmail.fre natural convection in an inclined cavity with right hot wavy wall and left cold flat wall. Das et al. [4] focused on natural convection inside an isothermal enclosure having a wavy bottom and ceiling. Thereafter, Dalal et al. [5] analyzed the natural convection problem in two-dimensional inclined enclosure with sinusoidal temperature profile on one wall. Gao et al. [6] investigated analytically and experimentally the thermal performance of cross-corrugated solar air-heaters. In a similar problem, numerical simulations of natural convection heat transfer and fluid flow have been performed respectively for horizontal and inclined solar collectors by Varol et al. [7,8]. Saha et al. [9] solved the natural convection problem for sinusoidal and inclined corrugation geometry and different heat source sizes. Recently, Bendehina et al. [10] reported a series of numerical simulations on laminar natural convection in inclined rectangular cavities with undulations and a sinusoidal temperature distribution on the cold wall. A thorough analysis conducted by Chin-Lung Chen et al. [11] highlighted the effects of various shaped concave enclosures on convection heat transfer. In another approach, Nasrin [12] investigated numerically laminar free convection in a solar collector with a flat cover and wavelike absorber filled with a water-alumina nanofluid. More 


\section{Nomenclature}

\begin{tabular}{|c|c|}
\hline$a, b$ & Aspect ratio $(a=H / L ; b=\lambda / L)$ \\
\hline$C_{p}$ & Specific heat at constant pressure $\left(\mathrm{J} \cdot \mathrm{kg}^{-1} \cdot \mathrm{K}^{-1}\right)$ \\
\hline$e(E)$ & Dimensional irradiance $\left(\mathrm{W} \cdot \mathrm{m}^{-2}\right)\left(\right.$ dimensionless, $\left.E=e / \sigma T_{\mathrm{H}}^{4}\right)$ \\
\hline$F_{i, j}$ & Shape factor \\
\hline$g$ & Gravitational acceleration $\left(\mathrm{m} . \mathrm{s}^{-2}\right)$ \\
\hline$G r$ & Grashof number $G r=R a / P r$ \\
\hline$H$ & Height (m) \\
\hline$j(J)$ & Dimensional radiosity $\left(\mathrm{W} \cdot \mathrm{m}^{-2}\right)$ (Dimensionless $\left.J=j / \sigma T_{\mathrm{H}}^{4}\right)$ \\
\hline$k$ & Thermal conductivity $\left(\mathrm{W} \cdot \mathrm{m}^{-1} \cdot \mathrm{K}^{-1}\right)$ \\
\hline$L$ & Length (m) \\
\hline$N u_{x}$ & Local Nusselt number \\
\hline$N u$ & Average Nusselt number \\
\hline$N_{r}$ & Dimensionless net radiation number $N_{r}=\sigma T_{H}^{4} /(k \Delta T / L)$ \\
\hline$p(P)$ & Dimensional pressure $(\mathrm{Pa})$ (Dimensionless $\left.P=p L^{2} /\left(\rho \nu^{2}\right)\right)$ \\
\hline $\operatorname{Pr}$ & Prandtl number $\operatorname{Pr}=\nu / \alpha$ \\
\hline$q_{r}\left(Q_{r}\right)$ & Dimensional net radiative flux density $\left(\mathrm{W} . \mathrm{m}^{-2}\right)\left(\right.$ Dimensionless $\left.Q_{r}=q_{r} /\left(\sigma T_{\mathrm{H}}^{4}\right)\right)$ \\
\hline$R a$ & Rayleigh number, $R a=g \beta\left(T_{\mathrm{H}}-T_{\mathrm{C}}\right) L^{3} /(\nu \alpha)$ \\
\hline$T$ & Temperature $(\mathrm{K})$ \\
\hline$v_{i}\left(V_{i}\right)$ & Dimensional velocity components $\left(\mathrm{m} . \mathrm{s}^{-1}\right)\left(\right.$ Dimensionless $\left.V_{i}=v_{i} L / \nu\right)$ \\
\hline \multicolumn{2}{|r|}{ Greek symbol } \\
\hline$\lambda$ & Wavy wall amplitude (m) \\
\hline$\phi$ & Inclination angle $\left(^{\circ}\right)$ \\
\hline$\rho$ & Density $\left(\mathrm{kg} \cdot \mathrm{m}^{-3}\right)$ \\
\hline$\alpha$ & Thermal diffusivity $\left(\mathrm{m}^{2} \cdot \mathrm{s}^{-1}\right)$ \\
\hline$\beta$ & Thermal expansion coefficient $\left(\mathrm{K}^{-1}\right)$ \\
\hline$\mu$ & Dynamic viscosity $\left(\mathrm{kg} \cdot \mathrm{s}^{-1} \cdot \mathrm{m}^{-1}\right)$ \\
\hline$\nu$ & Kinematic viscosity $\left(\mathrm{m}^{2} \cdot \mathrm{s}^{-1}\right)$ \\
\hline$\sigma$ & Stefan - Boltzmann constant $\sigma=5.67 \times 10^{-8}\left(\mathrm{~W} \cdot \mathrm{m}^{-2} \cdot \mathrm{K}^{-4}\right)$ \\
\hline$\epsilon$ & Emissivity \\
\hline$\theta, \Theta$ & Dimensionless temperature $\theta=\left(T-T_{\mathrm{C}}\right) /\left(T_{\mathrm{H}}-T_{\mathrm{C}}\right), \Theta=T / T_{H}$ \\
\hline$\Psi$ & Dimensionless stream function $\Psi=\psi / \nu$ \\
\hline$\delta_{i j}$ & Delta Kronecker \\
\hline \multicolumn{2}{|r|}{ Subscripts } \\
\hline $\mathrm{H}, \mathrm{C}$ & Hot and cold \\
\hline $\mathrm{L}, \mathrm{R}$ & Left, Right \\
\hline conv, rad & Convection and radiation \\
\hline Tot & Total \\
\hline
\end{tabular}

recently, Rahman et al. [13] analyzed numerically the flow behavior in a corrugated triangular solar collector filled with a nanofluid. On the other hand, Sahi et al. [14] have contributed to the understanding of the flow behavior, through numerical study of the effects of thermal boundary conditions and aspect ratio on the laminar natural convection in a rectangular solar collector. Amongst the conclusions drawn for these studies, the heat transfer is limited by the enclosure area and the inclination angle affects the flow and heat transfer and can be used as a control parameter.

The preceding literature review shows that available studies are generally limited to free convection without thermal radiation, although this always exists in air-filled solar collectors and cannot be ignored. Therefore, the interaction effects between surface radiation and natural convection in differentially heated enclosures have re- ceived considerable attention in recent years due to its relevance in several potential applications such as thermal insulations, electronic cooling systems and solar collectors. Some of these studies have investigated the conjugate heat transfer in cavities filled with a transparent medium whereas others have considered the participating media. Reviews of this subject can be found in the publications of Lauriat [15], Ridouane [16], Wang [17], Bouali [18], Mezrhab [19], Amraqui [20], Alvarado [21], Nouanegue [21], Ashish [23] and Vivek [24]. It is namely revealed that thermal radiation can strongly interact with the convection process and alters markedly the fluid flow characteristics. It's also found that the radiative Nusselt number is insensitive to the orientation of the cavity and natural convection coupled with radiation heat transfer presents a greater contribution compared with the forced convection systems. 

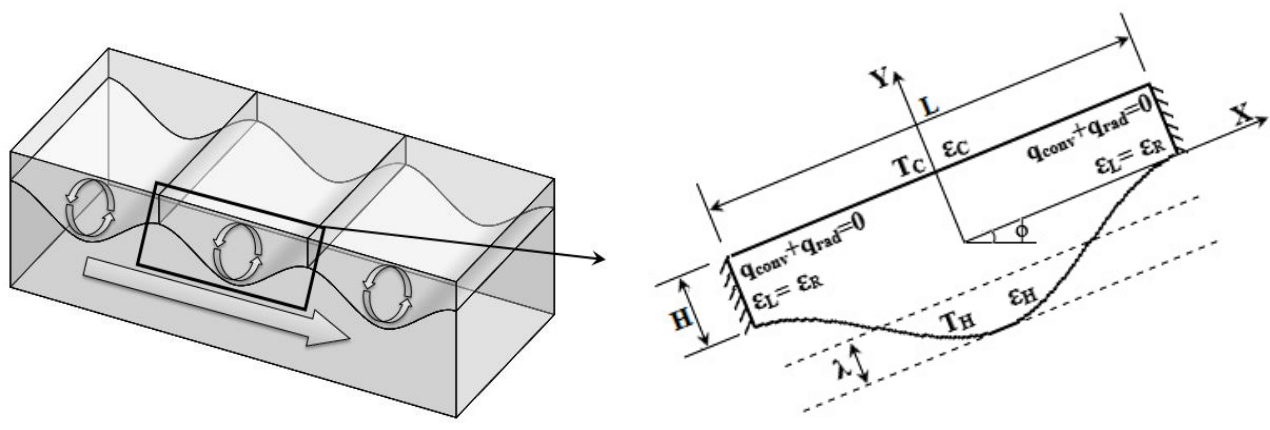

Fig. 1. Physical domain.

From the revised literature it can be seen that studies on natural convection coupled with thermal radiation inside complex shaped cavities are more scarce. Therefore, the fluid flow and heat transfer phenomena in a wavy tilted enclosure need a more comprehension. In this regard, special attention will be paid to the effects of Rayleigh number, surface emissivity and the tilt angle on the interaction between natural convection and surface radiation in a rectangular wavy enclosure.

\section{Problem description and mathematical formulation}

\subsection{Description of the physical model}

Computational domain and boundary conditions are shown schematically in Figure 1. The physical model of $2 \mathrm{D}$ shallow and tilted rectangular cavity filled with a transparent fluid, consists of a wavy bottom wall heated from below and cooled from the top at temperatures $T_{\mathrm{H}}=318 \mathrm{~K}$ and $T_{\mathrm{C}}=308 \mathrm{~K}$ respectively. Therefore, the two upper side walls are thermally insulated. All surfaces are assumed gray, diffuse and opaque with the emissivities $\left(\epsilon_{\mathrm{C}}\right),\left(\epsilon_{\mathrm{H}}\right)$ and $\left(\epsilon_{\mathrm{L}}=\epsilon_{\mathrm{R}}=\epsilon_{o}\right)$ for the top, bottom and vertical sides, respectively. Therefore, the shape of the wavy bottom wall is assumed to be sinusoidal, it's expressed as follow:

$$
\begin{aligned}
y=\lambda(\cos (m x+\pi)-1) \quad \text { with } \quad & m=2 \pi / L \\
\text { for } \quad & -L / 2 \leq x \leq L / 2
\end{aligned}
$$

In these figures, $H, L$ and $\phi$ are the height, the length and the inclination angle of the cavity while $\lambda$ is the amplitude of the wavy wall.

\subsection{Mathematical formulation}

The numerical model for heat transfer and fluid flow in the shallow enclosure was developed under some assumptions as steady state, laminar and incompressible Newtonian fluid. Viscous dissipation and compressibility effects are neglected. Also, the fluid properties are assumed constant except the density in the buoyancy terms of the momentum equations, which can be approximated by the Boussinesq approach.

The mathematical formulation governing the two dimensional fluid flow and heat transfer can be written on dimensionless form as:

$$
\frac{\partial V_{i}}{\partial X_{i}}=0
$$

$$
\begin{gathered}
V_{j} \frac{\partial V_{i}}{\partial X_{j}}=-\frac{\partial P_{i}}{\partial X_{i}}+\frac{\partial^{2} V_{i}}{\partial X_{j} \partial X_{j}}+\frac{R a}{P r} \theta \sin \left(\phi+\delta_{i 2} \frac{\pi}{2}\right) \\
V_{j} \frac{\partial \theta}{\partial X_{j}}=\frac{1}{\operatorname{Pr}} \frac{\partial^{2} \theta}{\partial X_{j} \partial X_{j}}
\end{gathered}
$$

Assuming the non-slip flow, the relevant dimensionless boundary conditions can be written as follows:

$$
V_{i}=0 \text { and } \theta=0 \text { and } \epsilon_{\mathrm{C}} \quad \text { (upper wall) }
$$

$$
V_{i}=0 \text { and } \theta=0 \text { and } \epsilon_{\mathrm{H}} \text { (bottom wavy wall) }
$$

$$
V_{i}=0 \text { and } \pm \frac{\partial \theta}{\partial X_{1}}+N_{r} Q_{r}=0 \text { and } \epsilon_{\mathrm{L}}=\epsilon_{\mathrm{R}}=\epsilon_{o}
$$

(right and left side wall)

In the above equations, $P$ and $\theta$ are the dimensionless pressure and temperature while $X_{i}$ and $V_{i}$ are the dimensionless Cartesian coordinates and corresponding velocity components respectively. The dimensionless quantities appearing in Equations (1)-(7) are the Rayleigh and Prandtl numbers respectively, defined as: $R a=$ $g \beta\left(T_{\mathrm{H}}-T_{\mathrm{C}}\right) L^{3} /(\nu \alpha)$ and $\operatorname{Pr}=\nu / \alpha$. While $Q_{r}$ and $N_{r}$ are the dimensionless net radiative flux and the net radiation number respectively, $Q_{r}=q_{r} /\left(\sigma T_{\mathrm{H}}^{4}\right)$ and $N_{r}=$ $\sigma T_{\mathrm{H}}^{4} /(k \Delta T / L)$.

\subsection{Radiation description}

The radiation heat transfer is computed using the radiosity formulation. All the enclosure walls are assumed to be gray, diffuse and opaque with different emissivities. 
The cavity is filled with a radiatively non-participating fluid (air, $\operatorname{Pr}=0.71$ ) such that, only the solid surfaces contribute to the radiation exchange. Thus, the radiative heat transfer is made only through the thermal boundary conditions.

The dimensionless rate of heat loss $\left(Q_{r, i}\right)$ from the $i$ th discrete surface determined as the difference between the outgoing radiosity and the incoming irradiance can be expressed as follow:

$$
Q_{r, i}=J_{i}-E_{i}
$$

Where the dimensionless quantities $J_{i}$ and $E_{i}$, are defined as:

$$
\begin{gathered}
E_{i}=\sum_{j=1}^{N}\left(J_{j} \cdot F_{i j}\right) \\
J_{i}=\epsilon_{i} \Theta_{i}^{4}+\left(1-\epsilon_{i}\right) E_{i}=\epsilon_{i} \Theta_{i}^{4}+\left(1-\epsilon_{i}\right) \sum_{j=1}^{N}\left(J_{j} \cdot F_{i j}\right)
\end{gathered}
$$

For numerical purposes, it is convenient to introduce the Knonecker delta $(\delta i j)$, so that Equation (10) can be rearranged as:

$$
\epsilon_{i} \Theta_{i}^{4}=\sum_{j=1}^{N}\left(\delta i j-\left(1-\epsilon_{i}\right) \cdot F_{i j}\right) J_{i} \quad i=1, \ldots, N
$$

where $(N)$ is the number of total radiative surfaces along the boundaries of the enclosures and $\epsilon_{i}$ is the emissivity of the $i$ th surface. The shape factor $F_{i j}$ from the $i$ th element to the $j$ th element of the enclosure is determined using Hottels crossed string method [25].

The mean Nusselt number, which is of a greater interest in engineering applications, is used to evaluate the heat transfer rate at the enclosure surfaces. To determine heat transfer characteristics at the enclosure walls, contributions of both convection and radiation should be taken into account. Thus, the averaged global Nusselt number along the cold wall is defined as the sum of the averaged convective and radiative Nusselt numbers.

$N u_{\text {Tot }}=N u_{\text {conv }}+N u_{\text {rad }}=-\int_{-\frac{1}{2}}^{\frac{1}{2}} \frac{\partial \theta}{\partial Y} \mathrm{~d} X+\int_{-\frac{1}{2}}^{\frac{1}{2}} N_{r} Q_{r} \mathrm{~d} X$

\section{Numerical procedure}

The mass, momentum and energy balance (Equations (2)-(4)) subjected to the specified boundary conditions (Equations (5)-(7)) are solved numerically using a developed solver based on a control-volume method under non-uniform grid system in $x$ and $y$ directions. The described solver uses a pressure correction based on iterative SIMPLER algorithm. The advective terms are discretized using a QUICK scheme whereas a second-order central difference scheme is applied for the diffusion terms (for more details, see [25]). To check the convergence of the sequential iterative solution, the normalized residual is calculated for the mass, momentum and energy equations. The convergence is obtained when the residual becomes smaller than $10^{-7}$.

\subsection{Grid dependency and code validation}

A curvilinear grid was generated to solve the problem treated. To find an appropriate grid size, a grid testing is performed using various grid combinations $(46 \times 46$ to $201 \times 201$ ) of control volumes.

For each grid size, maximum stream function and average Nusselt number are calculated and summarized in Figure $2 \mathrm{~b}$ for $R a=10^{6}, b=1 / 12, \phi=0$ and $\epsilon_{i}=0$. Throughout this investigation, $N u$ and $\Psi_{\max }$ remain almost the same for grids finer than $166 \times 166$ which satisfies the grid dependency. Hence, considering both the accuracy and the computational costs, most computations reported in the current work were performed with a multiple grid system of $166 \times 166$. The mesh is refined and focused near the walls where the most important gradients are located (cf. Fig. 3). Nevertheless, similar tests were conducted for other Rayleigh numbers and the grid size was adjusted accordingly.

Furthermore, extensive validations of the developed code for coupled radiation and natural convection in square cavity heated from bellow have been also done against the results reported by Ridouane et al. [16]. The computations have been performed in term of stream function and mean convective and radiative Nusselt numbers for various Rayleigh numbers and emissivities. As listed in Table 1, the comparisons are in good agreements, providing sufficient confidence in present computations.

\section{Results and discussion}

Such as this investigation is dictated by the need to understand the heat transfer mechanisms occurring usually in air solar collectors; different scenarios for conjugate natural convection and surface radiation in a tilted slender cavity having one wavy wall were explored. For a comparison purpose, Rayleigh number, aspect ratio (amplitude), inclination angle and surface emissivities $\left(\epsilon_{\mathrm{C}}, \epsilon_{\mathrm{H}}\right.$, and $\epsilon_{\mathrm{o}}$ ) are applied as the main effective parameters for the combined mode of heat transfer.

\subsection{Temperature and fluid pattern (streamlines and isotherms)}

\subsubsection{Effect of the Rayleigh number and the wavy wall amplitude}

Buoyancy driven flow and temperature field inside the enclosure are given by means of streamlines and isotherms. Figures $4 \mathrm{a}-4 \mathrm{~b}$, illustrate the effect of Rayleigh number and the wavy wall amplitude on the flow pattern 


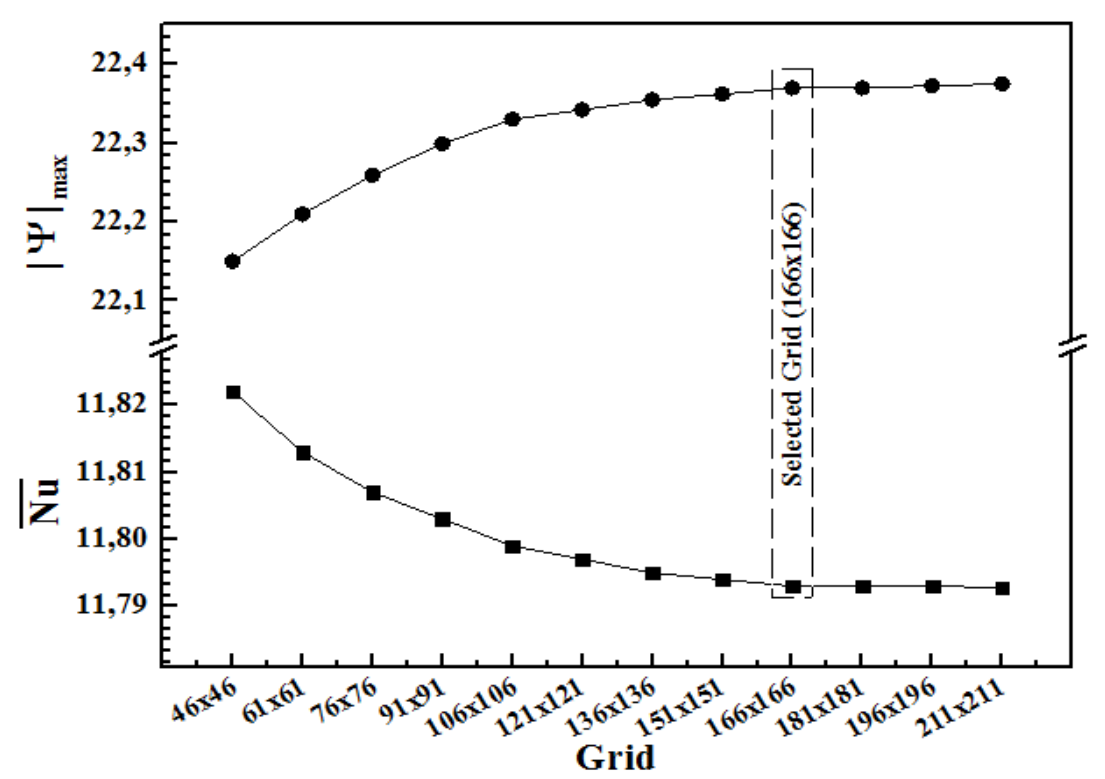

Fig. 2. Grid dependency $\left(R a=10^{6}, b=1 / 12, \phi=0\right.$ and $\epsilon_{\mathrm{L}}=\epsilon_{\mathrm{R}}=\epsilon_{\mathrm{H}}=\epsilon_{\mathrm{C}}=0$.

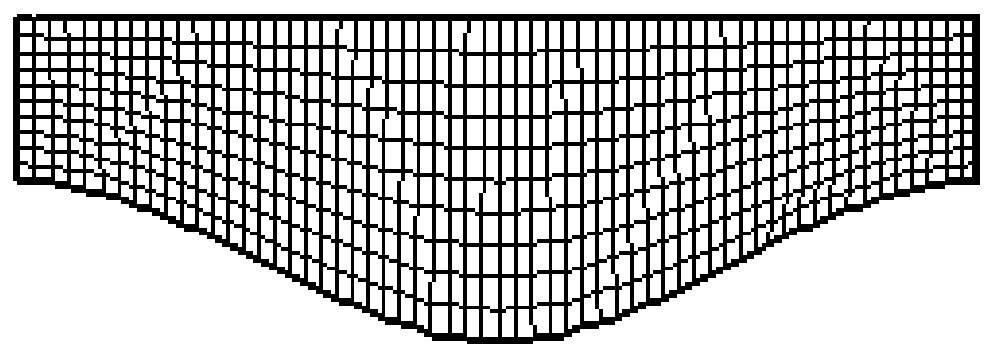

Fig. 3. Detail of the computational grid within the enclosure.

Table 1. Comparison between the present study and reference [16] for natural convection and radiation in a square cavity.

\begin{tabular}{|c|c|c|c|c|c|c|c|}
\hline & $R a$ & $\epsilon$ & $\Psi_{\max }$ & $\Psi_{\min }$ & $N u_{\text {conv }}$ & $N u_{\mathrm{rad}}$ & $\overline{N u_{\text {total }}}$ \\
\hline Reference $[16]$ & & & 12.137 & -110.286 & 7.617 & 0 & 7.617 \\
\hline Present study & $2 \times 10^{6}$ & 0 & $\begin{array}{l}12.488 \\
(2.892)\end{array}$ & $\begin{array}{c}-113.139 \\
(2.587)\end{array}$ & $\begin{array}{l}7.586 \\
(0.407)\end{array}$ & 0 & $\begin{array}{l}7.586 \\
(0.407)\end{array}$ \\
\hline Reference $[16]$ & & & 6.612 & -74.921 & 6.267 & 6.599 & 12.866 \\
\hline Present study & $10^{6}$ & 0.5 & $\begin{array}{r}6.440 \\
(2.601) \\
\end{array}$ & $\begin{array}{c}-76.202 \\
(1.710) \\
\end{array}$ & $\begin{array}{c}6.081 \\
(2.968) \\
\end{array}$ & $\begin{array}{r}6.706 \\
(1.614) \\
\end{array}$ & $\begin{array}{l}12.787 \\
(0.614) \\
\end{array}$ \\
\hline Reference $[16]$ & & & 3.827 & -45.372 & 4.722 & 11.462 & 16.183 \\
\hline Present study & $4 \times 10^{5}$ & 1 & $\begin{array}{c}3.721 \\
(2.770)\end{array}$ & $\begin{array}{c}-46.434 \\
(2.341)\end{array}$ & $\begin{array}{c}4.715 \\
(0.148)\end{array}$ & $\begin{array}{l}11.283 \\
(1.562)\end{array}$ & $\begin{array}{l}15.998 \\
(1.143)\end{array}$ \\
\hline
\end{tabular}

Note. The values in ( ) are the absolute difference in \%.

and temperature contours in the enclosure for both the simple free convection and the combined mode. The circulation force of the flow within the cavity takes place by virtue of thermal buoyancy which is represented by the Rayleigh number $R a$. For small values of $R a\left(10^{4}\right)$, the fluid motion involves two primary and symmetric recirculating eddies of relatively weak velocity extending throughout the partitioned cavity with clockwise and anti-clockwise rotations $\left(0.0361 \leq \Psi_{\max } \leq 0.2303\right)$. The isotherms plots are smooth curves which cover the entire enclosure and present a symmetric behavior about the vertical axis indicating that the conduction is the dominant heat transfer mechanism. The isotherms values change smoothly from the hot to the cold wall with a decreasing from the bottom to the top along the vertical center line, thermal stratification reigns in the entire domain.

An increase of $R a\left(10^{6}\right)$, due to the important temperature gradient generates the faster recirculation rolls $\left(15.8846 \leq \Psi_{\max } \leq 27.2007\right)$. The convection increases significantly and becomes stronger, such as isotherms show plume-like shape and a multi-cell structure prevails 

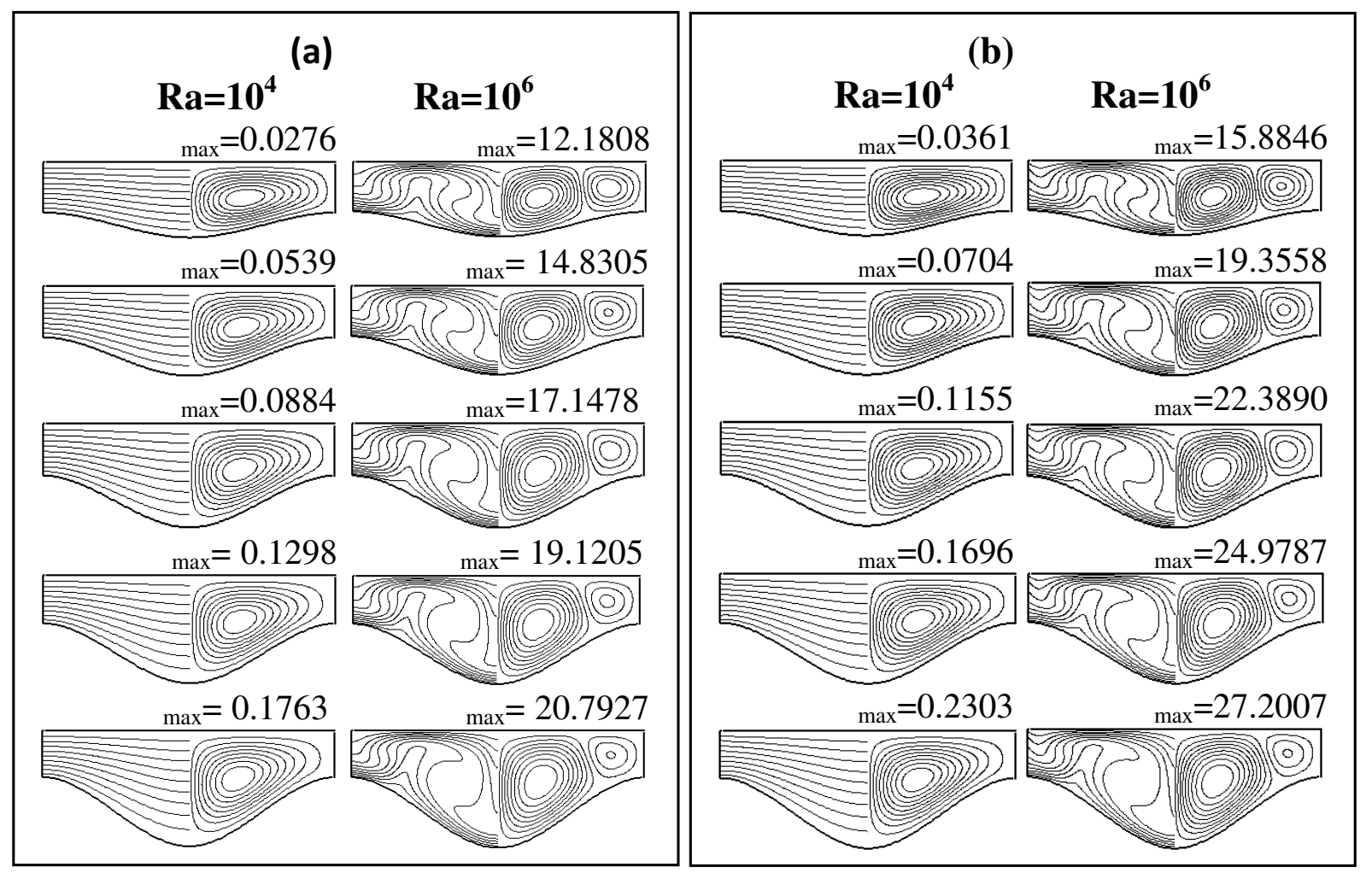

Fig. 4. Streamlines (right) and isotherms (left) for horizontal collector $\phi=0$ and $b=1 / 24,1 / 16,1 / 12,5 / 48$ and $1 / 8$. (a) $\epsilon_{i}=0$ (pure convection) (b) $\epsilon_{\mathrm{C}}=0.9, \epsilon_{\mathrm{H}}=1$ and $\epsilon_{\mathrm{o}}=0.5$ (pure convection).

in the enclosure. By using the same boundary conditions for the left and right sides, the pairs of cells are close to each other and present a similar symmetric shape about the vertical center line. Each pair of cells rotates in the clockwise and in counterclockwise direction, respectively. Thus, the appearance of the plume is expected to improve the heat transfer and promotes the convection mechanism against conduction. It's clearly observed that the buoyancy strength induces the increasing vortices for higher $R a$ number; this is owing to the dominating influence of the convective current in the cavity.

The streamlines and isotherms structures change with the variation of the dimensionless wave amplitude $(b)$. The flow is accelerated when the shape parameter $(b)$ increases accompanied by a significant distortion in the temperature contours, especially in the core region. The parameters governing the plume formation are Rayleigh number and aspect ratio $(b)$. Moreover, the temperature contours are concentrated and compressed toward isothermal walls.

It is noteworthy that, according to the mathematical model, especially in view of the boundary conditions it is clear that surface radiation does not alter the flow field in the core region. Indeed, when $\epsilon_{i}=0$ (pure convection, Fig. 4a) isotherms are normal to the insulated walls whereas in coupled mode $\left(\epsilon_{i} \neq 0\right.$, Fig. $\left.4 \mathrm{~b}\right)$ the isotherms appear inclined due to the radiative heat exchange. This, in turn, alters significantly the gradient temperature near the adiabatic walls. So the temperature distribution at the adiabatic walls depends on the heat exchange by both convection and surface radiation.

\subsubsection{Effect of the tilt angle}

Figure 5 shows the effect of the tilt angle $(\phi)$ on the flow patterns and isotherms within the enclosure for aspect ratio $b=1 / 12$ and various Rayleigh numbers $\left(10^{3}\right.$ and $10^{7}$ ) when $\epsilon_{\mathrm{C}}=0.9, \epsilon_{\mathrm{H}}=1$ and $\epsilon_{o}=0.5$. At $\phi=0$, whatever the number of Rayleigh, the results in terms of fluid flow and temperature distribution are symmetrical along the vertical axis passing through the center of the cavity as mentioned above.

For small Rayleigh numbers $\left(R a=10^{3}\right)$, the variation of the inclination angle changes the flow structure from bi-cellular behavior obtained for horizontal case $(\phi=0)$ to unicellular structure occupying the entire cavity for inclined collector $(\phi>0)$. The flow is slightly accelerated and rotates in clockwise and the isotherms are smooth curves covering the entire enclosure. For largest buoyancy forces $\left(R a=10^{7}\right)$, increasing the tilt angle leads to slow down the fluid flow so its strength decreases $\left(\phi=0 \Psi_{\max }=76.2203 ; \phi=15 \Psi_{\max }=55.8704\right.$; $\phi=30 \Psi_{\max }=70.0381 ; \phi=60 \Psi_{\max }=57.7181$ and $\left.\phi=90 \Psi_{\max }=48.5412\right)$. This generates a single-cell structure, by merging primary cells with the secondary ones, also for highest tilt angles values $(\phi=60)$, minor cells are formed within the main circulation cell. Thermally, a significant distortion of thermal plume appears so that 


\section{$\phi=0 \quad \phi=15 \quad \phi=30 \quad \phi=60 \quad \phi=90$ \\ $\mathbf{R a}=10^{3}$}

(a)
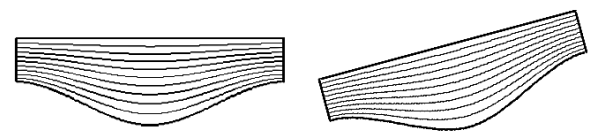

(b)
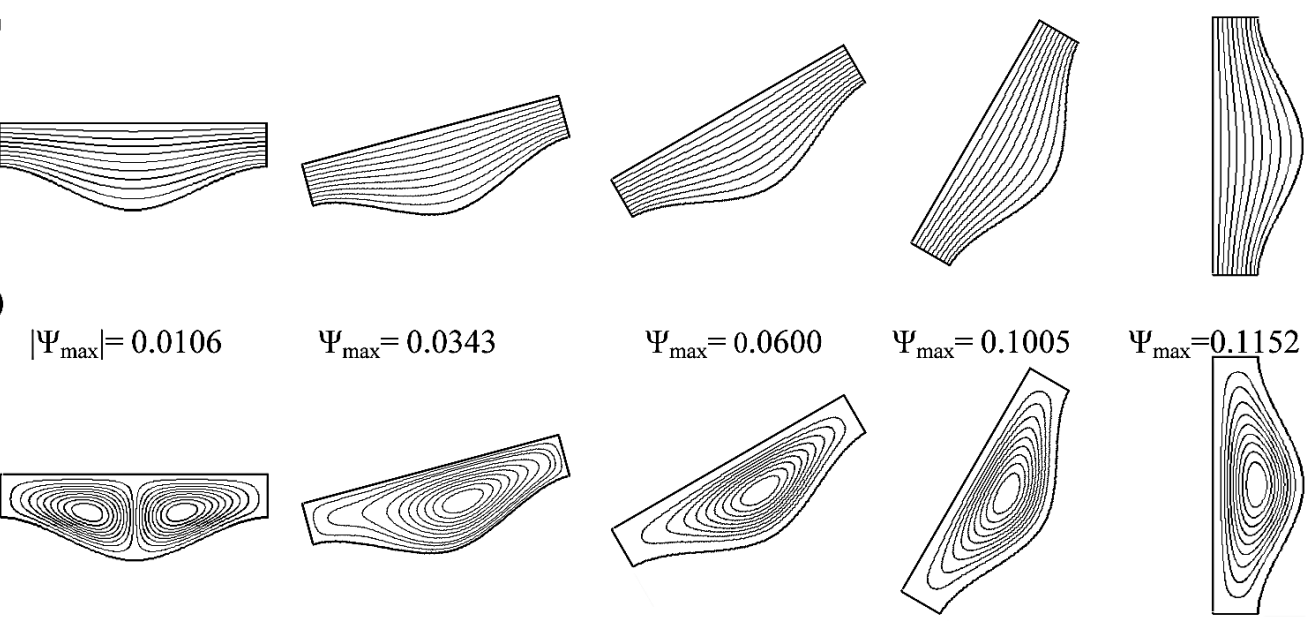

\section{$\mathbf{R a}=10^{7}$}

(a)
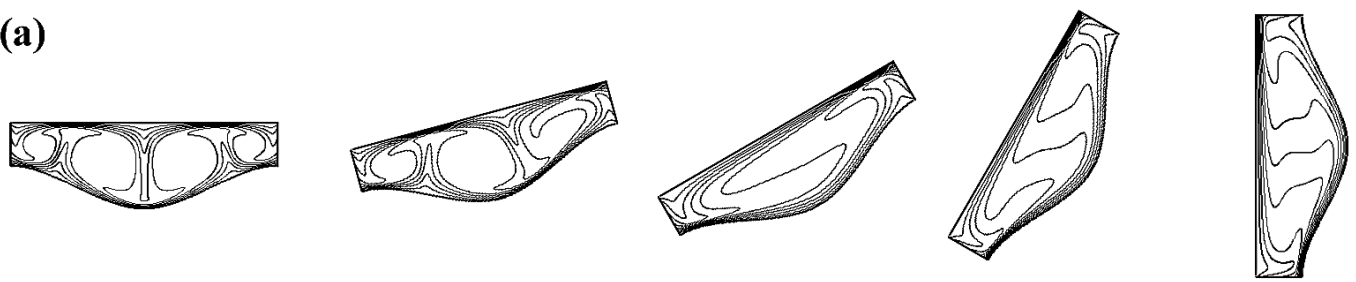

(b)
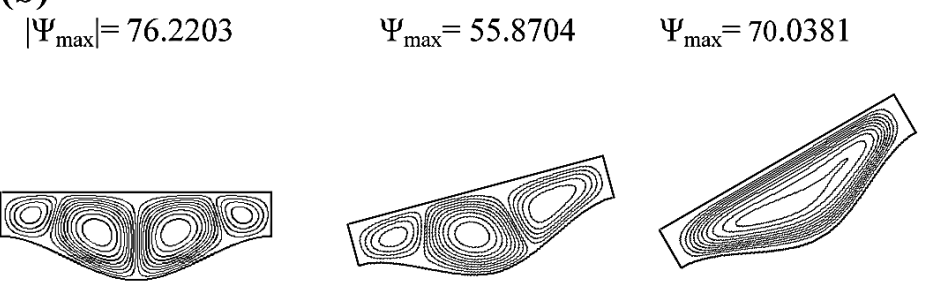

$\Psi_{\max }=57.7183$

$\Psi_{\max }=48.5412$
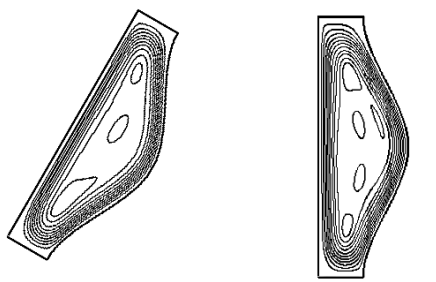

Fig. 5. Effect of inclination angle $(\phi)$ on isotherms (a) and streamlines (b): $a=1 / 6$ and $b=1 / 12$ and $\epsilon_{\mathrm{C}}=0.9, \epsilon_{\mathrm{H}}=1$ and $\epsilon_{o}=0.5$.

isotherms are deformed in the sense of inclination. It follows the appearance of two thermal boundary layers characterized by strong thermal gradients, located in the upper right and lower left parts, respectively.

\subsubsection{Effect of surface emissivities}

Figure 6 allows us to analyse the surface radiation effect on isotherms and streamlines inside the enclosure for horizontal and vertical collector, respectively for $\phi=0^{\circ}$ and $\phi=90^{\circ}$. It's clear that the surface radiation for the emissivity $\left(\epsilon_{i} \geq 0.5\right)$ has minimal effect on the streamlines and isotherms. On the other hand, a slight variation in emissivity affects the flow structure and the temperature distribution only near the insulated walls. Indeed, for low emissivity $\left(\epsilon_{i} \leq 0.5\right)$, the isothermal lines are vertical to the insulated walls, while for higher emissivity $\left(\epsilon_{i} \geq 0.5\right)$ isotherms appear inclined. Note that the variation of the emissivity of cold wall has a greater effect on the flow structure and the temperature distribution, compared with the effect of other emissivities $\left(\epsilon_{\mathrm{H}} ; \epsilon_{\mathrm{O}}\right)$.

\subsection{Heat transfer}

\subsubsection{Local Nusselt number}

Heat transfer rate is presented in terms of local and average Nusselt numbers along the cold wall. Figure 7 depicts the variation of local Nusselt number in pure free convection (Figs. 7a-7b) and combined surface radiation 
$\varepsilon_{\mathrm{i}}=0.1$
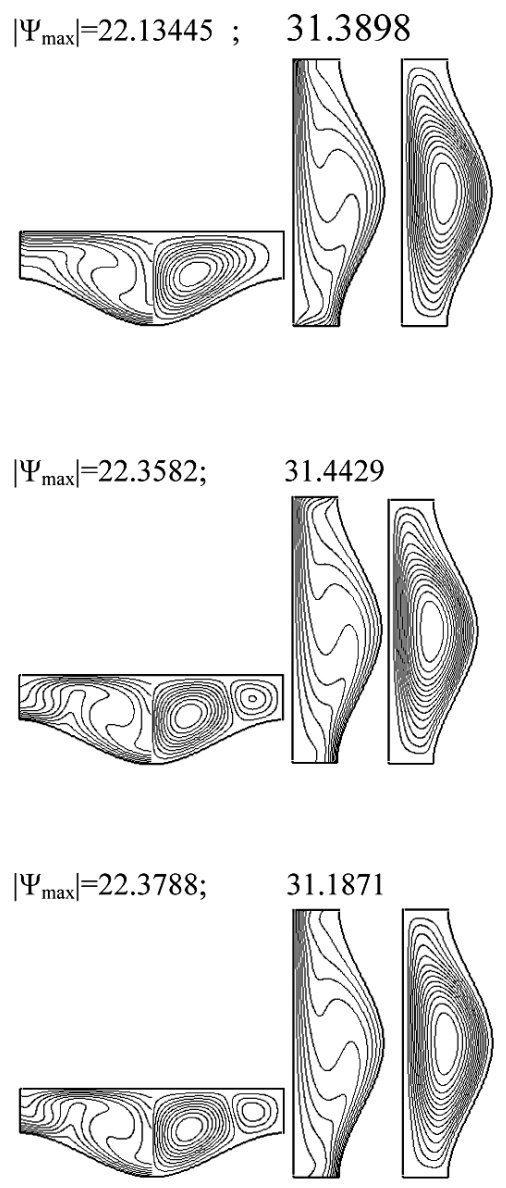

$\varepsilon_{\mathrm{i}}=0.5$

(a)

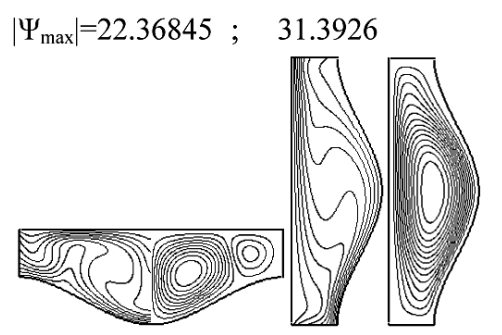

(b)

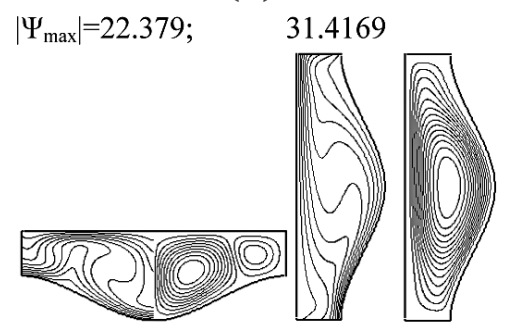

(c)

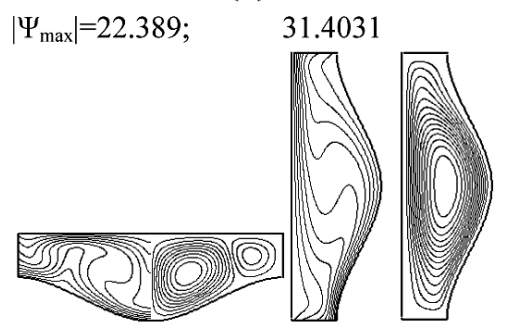

$\varepsilon_{\mathrm{i}}=0.9$
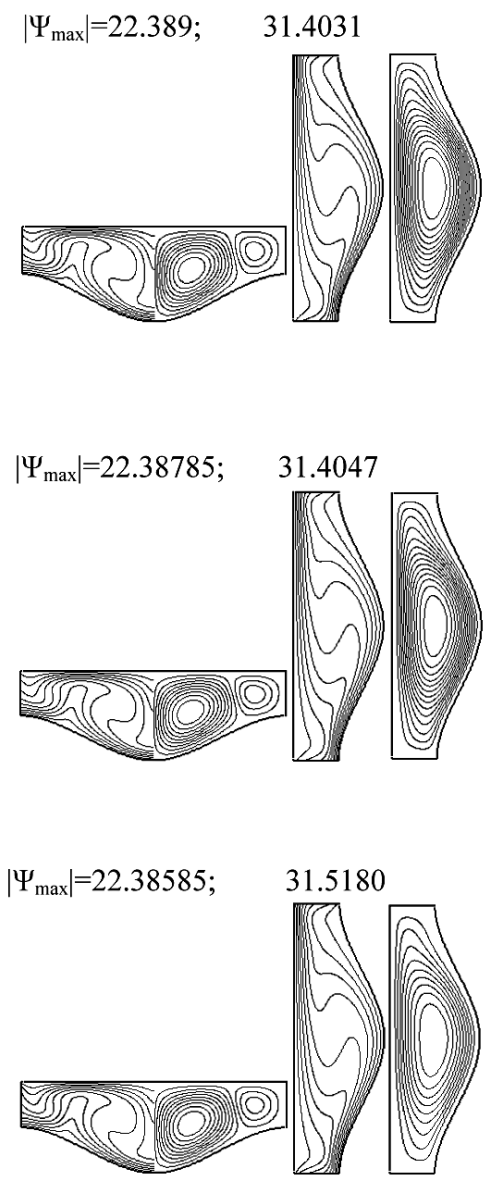

Fig. 6. Effect of surface emissivity on streamlines (right) and isotherms (left) for $R a=10^{6}, a=1 / 6 ; b=1 / 12 ; \phi=0$ and 90 . (a) $\epsilon_{\mathrm{H}}=1 ; \epsilon_{o}=0.5$ and $\epsilon_{\mathrm{C}}=\epsilon_{i}=0.1,0.5$ and 0.9 . (b) $\epsilon_{\mathrm{C}}=0.9 ; \epsilon_{o}=0.5$ and $\epsilon_{\mathrm{H}}=\epsilon_{i}=0.1,0.5$ and 0.9 . (c) $\epsilon_{\mathrm{H}}=1 ; \epsilon_{\mathrm{C}}=0.9$ and $\epsilon_{o}=\epsilon_{i}=0.1,0.5$ and 0.9 .

and free convection (Figs. 7c-7f), respectively. The curves drawn against $X$ (Figs. 7a and 7c-7e) show that for all Rayleigh numbers, the local Nusselt values are symmetric with respect $X=0$. The peaks observed in convective Nusselt numbers, correspond to the tightening of the thermal boundary layer along the cold wall. The minimum heat transfer rate, resulting from the relaxation of the thermal boundary layer occurs at the middle wall as seen from streamlines and isotherms contours. As a result of decreasing $R a$ number, the convective heat transfer rate along this wall decreases such that these curves become gradually smooth and tend to conduction regime results. The contribution of radiative walls is also shown in Figures $7 \mathrm{c}-7 \mathrm{f}$, thus for a fixed $R a$ number the local radiative Nusselt number follows a parabolic trend along the cold wall. It is noteworthy that in the absence of thermal radiations the total Nusselt number coincides with the convective Nusselt number (Figs. 7a-7b).

The variation of the local Nusselt numbers with the tilt angle $(\phi)$ is shown in Figure $7 \mathrm{~d}$. As predicted, the local convective Nusselt number $\left(N u_{x_{\text {conv }}}\right)$ changes from a symmetrical shape for horizontal configuration to asym- metrical shape for inclined cavity $(\phi>0)$. The same effect is noted when changing the dimensionless amplitude $(b)$, with a slight variation in the convective Nusselt values, as shown in Figures $7 \mathrm{e}$ and $7 \mathrm{f}$. It should be observed that the local radiative Nusselt number does not change with $\phi$ or $b$.

\subsubsection{Average Nusselt number}

The variation of average Nusselt number calculated by integrating the local Nusselt distribution is utilized to evaluate the overall heat transfer rate for different values of $R a$ as illustrated in Figures 8 and 9 and Tables 2 and 3 . To highlight the effects produced by changing the wavy wall amplitude $(\lambda)$ on the heat transfer at the transparent cover, Figures $8 \mathrm{a}-8 \mathrm{c}$ depict the mean convective and radiative Nusselt numbers following different inclination angles. Regardless the dimensionless amplitude $(b)$, when the heat transfer is only due to conduction, the Rayleigh number does not entail any significant variation on convective heat transfer and $\left(N u_{\text {conv }}\right)$ remains unchanged 
(a)

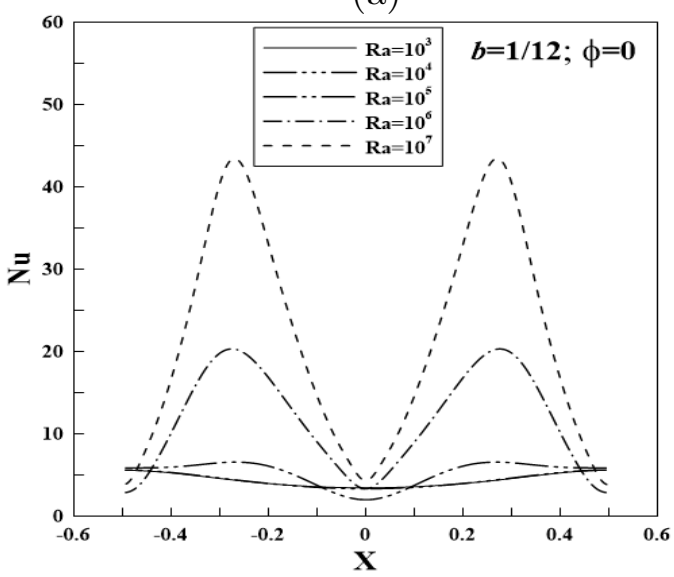

(c)

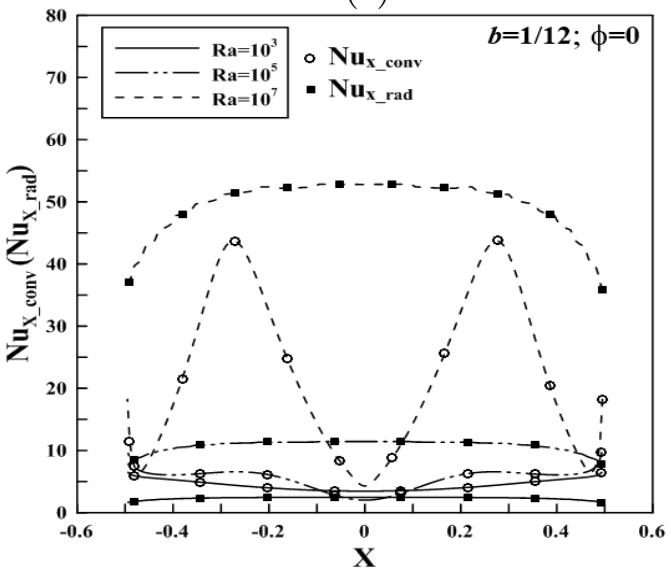

(e)

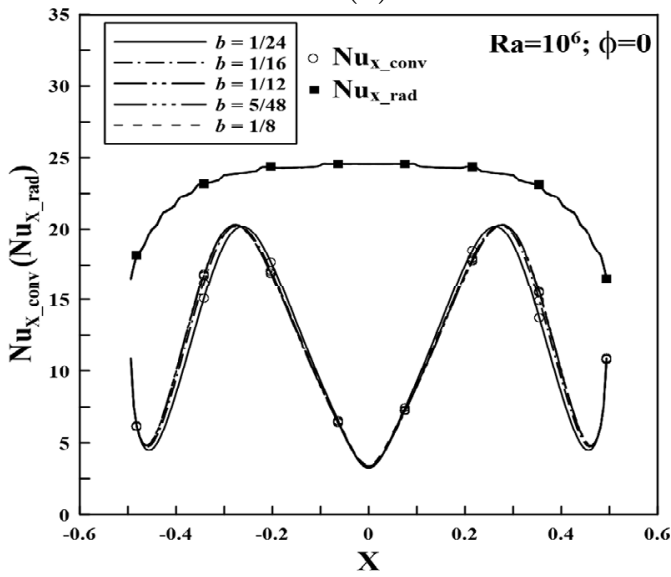

(b)

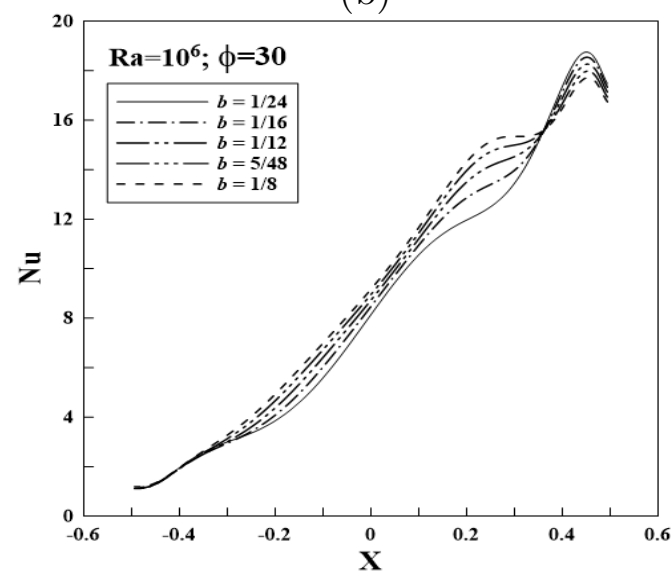

(d)

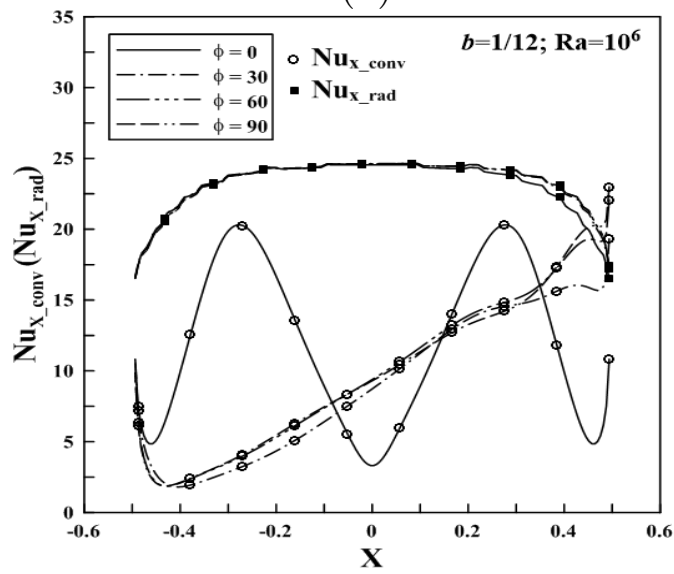

(f)

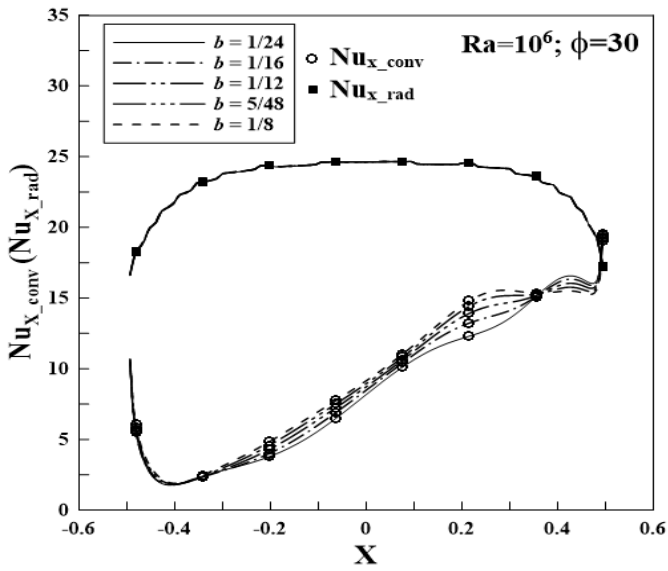

Fig. 7. Local Nusselt numbers versus the distance $X$ : (a) and (b) pure convection $\left(\epsilon_{i}=0\right)-(\mathrm{c})$ (d) (e) and (f) coupled mode $\left(\epsilon_{\mathrm{C}}=0.9, \epsilon_{\mathrm{H}}=1\right.$ and $\left.\epsilon_{o}=0.5\right)$.

whether increasing $R a$. Also, when the heat transfer is mainly due to convection, increasing Rayleigh number produces the higher buoyancy-induced flow within the enclosure, consequently the higher convective Nusselt number. Furthermore, it is observed that $\left(N u_{\text {conv }}\right)$ depends closely on both the amplitude of the wall and the inclination of the cavity. So, when the heat transfer is only due to conduction, increasing the aspect ratio $(b)$ reduces the mean convective Nusselt number. The reversed phenomenon is observed when the heat transfer is mainly due to convection, i.e. an increase in $(b)$ raises the convective Nusselt number.

Based on the results obtained numerically throughout this work, we could see considerable influence of the 
Table 2. Averaged global $\left(N u_{\text {Tot }}\right)$ and convective $\left(N u_{\text {Conv }}\right)$ Nusselt numbers: Comparison between simulation (Sim.) and correlation (Cor.) data for $b=1 / 12$.

\begin{tabular}{|c|c|c|c|c|c|c|c|c|c|c|c|c|}
\hline$(\phi)$ & \multicolumn{2}{|c|}{0} & \multicolumn{2}{|c|}{15} & \multicolumn{2}{|c|}{30} & \multicolumn{2}{|c|}{45} & \multicolumn{2}{|c|}{60} & \multicolumn{2}{|c|}{75} \\
\hline \multicolumn{13}{|c|}{$N u_{\text {Tot }}$ : Combined mode $\left(\epsilon_{\mathrm{C}}=0.9, \epsilon_{\mathrm{C}}=1\right.$ and $\left.\epsilon_{o}=0.5\right)$} \\
\hline Ra & Res. & Cor. & Res. & Cor. & Res. & Cor. & Res. & Cor. & Res. & Cor. & Res. & Cor. \\
\hline $10^{4}$ & 9.50 & 9.56 & 9.50 & 9.40 & 9.50 & 9.46 & 9.51 & 9.50 & 9.51 & 9.57 & 9.52 & 9.65 \\
\hline $10^{6}$ & 35.12 & 35.44 & 34.81 & 35.24 & 32.51 & 33.28 & 32.91 & 33.60 & 33.19 & 34.01 & 33.54 & 34.44 \\
\hline \multicolumn{13}{|c|}{$N u_{\text {conv }}:$ Pure convection $\left(\epsilon_{i}=0\right)$} \\
\hline $10^{4}$ & 4.39 & 4.44 & 4.39 & 4.45 & 4.40 & 4.47 & 4.40 & 4.54 & 4.41 & 4.59 & 4.41 & 4.61 \\
\hline $10^{6}$ & 11.79 & 11.82 & 11.32 & 11.27 & 9.01 & 9.22 & 9.55 & 9.55 & 9.82 & 9.72 & 9.88 & 9.77 \\
\hline
\end{tabular}

Table 3. Effect of surface emissivity on $N u_{\text {total }}\left(\phi=0^{\circ}\right.$ and $\left.R a=10^{6}\right) A:\left(\epsilon_{\mathrm{H}}=1, \epsilon_{\mathrm{o}}=0.5, \epsilon_{i}=\epsilon_{\mathrm{C}}\right) ; B:\left(\epsilon_{\mathrm{C}}=0.9, \epsilon_{\mathrm{o}}=0.5\right.$, $\left.\epsilon_{i}=\epsilon_{\mathrm{H}}\right) ; C:\left(\epsilon_{\mathrm{H}}=1, \epsilon_{\mathrm{C}}=0.9, \epsilon_{i}=\epsilon_{\mathrm{o}}\right)$.

\begin{tabular}{cccccccc}
\hline & $N u_{\text {total }}$ & $\epsilon_{i}=0$ & $\epsilon_{i}=0.2$ & $\epsilon_{i}=0.4$ & $\epsilon_{i}=0.6$ & $\epsilon_{i}=0.8$ & $\epsilon_{i}=1$ \\
\hline \multirow{4}{*}{$A=1 / 24$} & 12.929 & 18.089 & 23.146 & 28.102 & 32.622 & 37.326 \\
& $b=1 / 16$ & 10.536 & 15.843 & 22.446 & 27.593 & 32.589 & 37.472 \\
& $b=1 / 12$ & 10.896 & 16.109 & 22.533 & 27.680 & 32.669 & 37.550 \\
& $b=5 / 48$ & 11.153 & 16.384 & 22.588 & 27.724 & 32.713 & 37.592 \\
& $b=1 / 8$ & 11.345 & 16.562 & 22.671 & 27.760 & 32.738 & 37.613 \\
\hline \multirow{4}{*}{$B=1 / 24$} & 12.448 & 17.532 & 22.295 & 26.763 & 30.960 & 34.907 \\
& $b=1 / 16$ & 12.552 & 17.726 & 22.527 & 26.994 & 31.157 & 35.043 \\
& $b=1 / 12$ & 12.623 & 17.912 & 22.759 & 27.216 & 31.325 & 35.122 \\
& $b=5 / 48$ & 12.669 & 18.093 & 22.989 & 27.429 & 31.472 & 35.166 \\
& $b=1 / 8$ & 12.712 & 18.265 & 23.202 & 27.619 & 31.595 & 35.187 \\
\hline \multirow{4}{*}{$C$} & $b=1 / 24$ & 34.998 & 34.931 & 34.908 & 34.909 & 34.923 & 34.944 \\
& $b=1 / 16$ & 35.121 & 35.061 & 35.043 & 35.047 & 35.062 & 35.083 \\
& $b=1 / 12$ & 35.196 & 35.139 & 35.122 & 35.125 & 35.139 & 35.159 \\
& $b=5 / 48$ & 35.238 & 35.183 & 35.165 & 35.168 & 35.181 & 35.200 \\
& $b=1 / 8$ & 35.254 & 35.202 & 35.186 & 35.193 & 35.204 & 35.225 \\
\hline
\end{tabular}
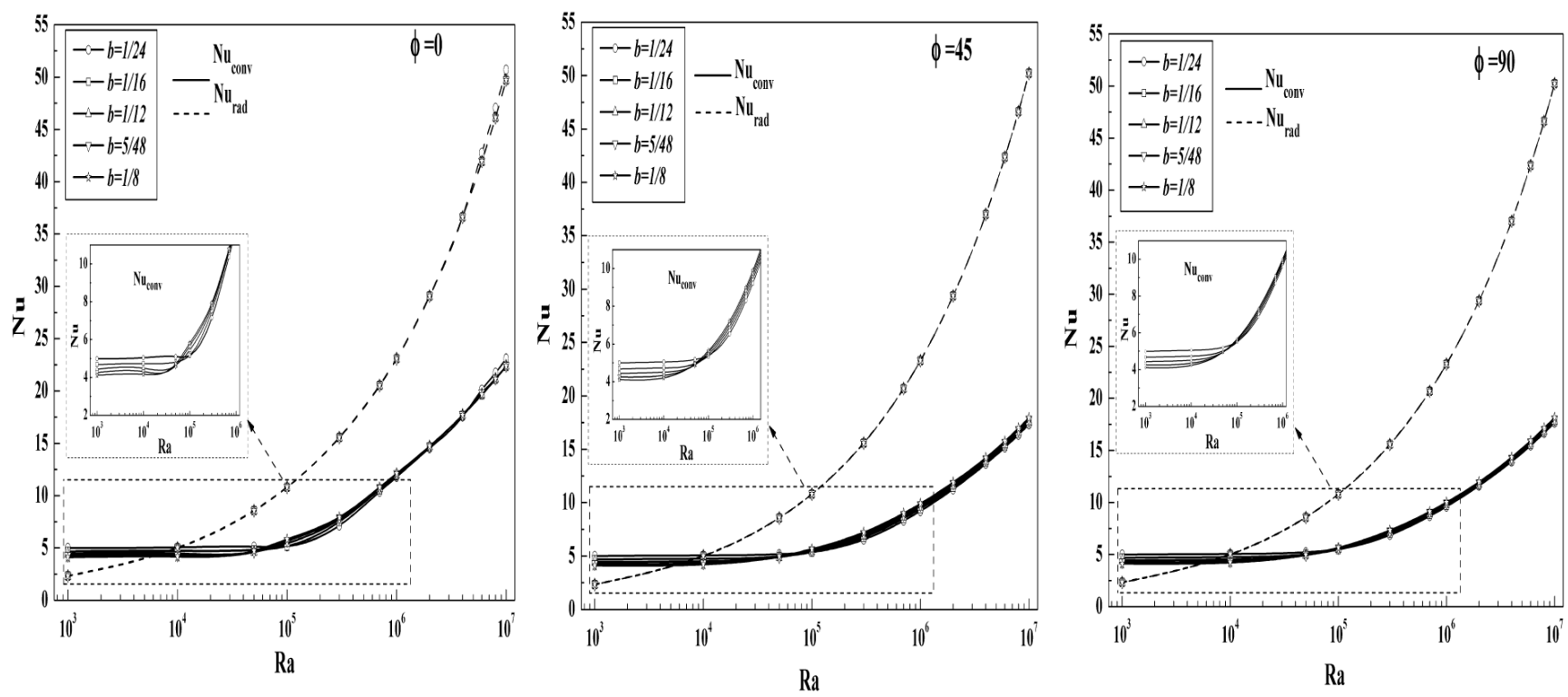

Fig. 8. Influence of aspect ratio $(b)$ on the convective and radiative Nusselt numbers for $\phi=0^{\circ}, 45^{\circ}$ and $90^{\circ}\left(\epsilon_{\mathrm{C}}=0.9, \epsilon_{\mathrm{H}}=1\right.$ and $\left.\epsilon_{\mathrm{o}}=0.5\right)$. 


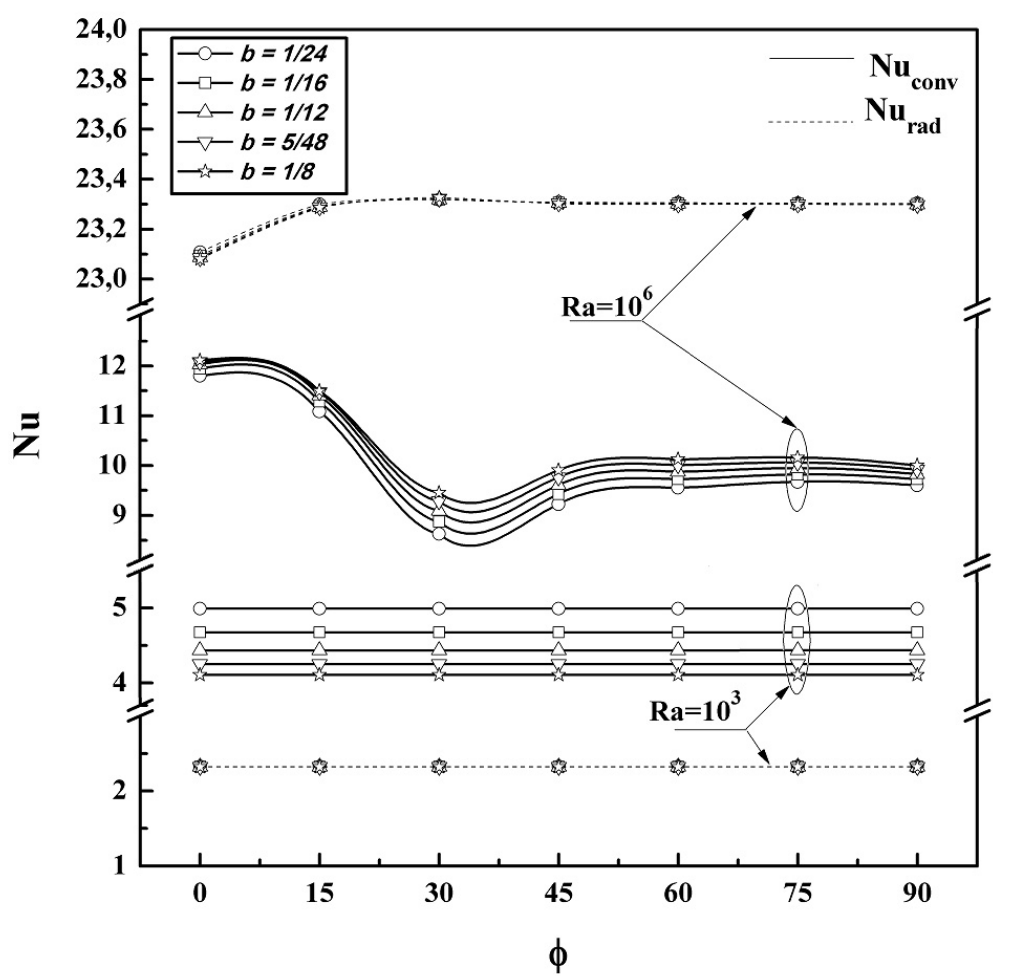

Fig. 9. Tilt angle $(\phi)$ and dimensionless amplitude $(b)$ effects on average convective and radiative Nusselt number for $\epsilon_{\mathrm{C}}=0.9$, $\epsilon_{\mathrm{H}}=1$ and $\epsilon_{\mathrm{o}}=0.5$.

inclination angle and aspect ratio and flow regimes on the Nusselt number. Therefore, an empirical adjustment of the test data was carried out, which allowed to deduce two correlations corresponding respectively to cases pure convection and to coupled convection-surface radiation modes. Table 2 summarizes the comparison between simulation and correlation data for the global Nusselt number defined as the sum of convective and radiative Nusselt-numbers. In pure convection $\left(\epsilon_{i}=0\right)$ the total Nusselt number coincides with the convective Nusselt. As previously shown, the radiation increases the total heat transfer markedly. For the considered configuration, the following correlations are suggested to approximate the convective and global Nusselt numbers. These correlations are expressed as:

- Coupled mode $\left(N u_{\text {Total }}\right)$

$$
\begin{aligned}
N u_{\text {Total }} & =\frac{0.972+A_{1}(\cos (\phi))^{n}}{\sqrt{b}} \\
& +\left(0.901+A_{2}(\cos (\phi))^{1.281}\right) \sqrt{b} R a^{\frac{1-b}{2.642}}
\end{aligned}
$$

- Pure convection $(N u)$

$$
\begin{aligned}
& N u=\left(\left(4.751-0.216 t(\cos (\phi))^{2.939}\right) \sqrt{1-b}\right) \\
& -\left(12.490+A_{1}\left(\cos (\phi)^{n}\right)\right)\left(\mathrm{e}^{-\left(\frac{A_{2}+A_{3}(\cos (\phi))^{n}}{1-b}\right) R a \times 10^{-7}}-1\right)
\end{aligned}
$$

\begin{tabular}{ccccc}
\hline & \multicolumn{2}{c}{$N u_{\text {conv }}$} & \multicolumn{2}{c}{$N u_{\text {tot }}$} \\
\cline { 2 - 5 } & $\phi<30$ & $\phi \geq 30$ & $\phi<30$ & $\phi \geq 30$ \\
\hline$A_{1}$ & 6.988 & -0.198 & -0.106 & 0.031 \\
$A_{2}$ & 3.716 & 4.972 & 0.03 & -0.053 \\
$A_{3}$ & 0.726 & -0.981 & - & - \\
$n$ & 5 & 5 & -10 & 5 \\
\hline
\end{tabular}

where $R a$ is the Rayleigh number, $b$ the dimensionless wavy wall amplitude and $\phi$ the tilt angle of the collector. The correlation Eqs valid for the following range of parameters $R a \leq 8 \times 10^{6}, 1 / 24 \leq b \leq 1 / 8$ and $0^{\circ} \leq \phi \leq 90^{\circ}$ are quite agreed with the numerical data obtained from the simulations with an error not exceeding $5 \%$.

These findings are confirmed in Figure 9, for all dimensionless amplitude $(b)$. The tilt angle has significant effect on the convective Nusselt number when convection prevails in the entire cavity $\left(R e=10^{6}\right)$. Indeed, $N u_{\text {conv }}$ decreases sharply for an inclination angle included between $0^{\circ}$ and $40^{\circ}$ and increases in the range $40^{\circ}-50^{\circ}$ to remain constant for higher values. Furthermore, the aspect ratio (b) has an insignificant effect on $N u_{\text {rad }}$ as previously noted (due to reference lengths adopted). In addition, the convective Nusselt number is greater than the radiative Nusselt number for low values of Rayleigh number, the opposite phenomenon is observed for large values of $R a$.

Finally, Table 3 summarizes the effect of surface emissivity of the cold wall (A), hot wall (B) and insulated wall $(\mathrm{C})$, respectively, on the average Nusselt for $\phi=0^{\circ}$ and $R a=10^{6}$. As shown, isolated wall emissivity has little effects on the total Nusselt number which remains substantially constant $\left(N u_{\text {Tot }}=35\right)$ regardless of the 
ratio $b$. In other cases (A) and (B), the total Nusselt number increases gradually with the increasing in the corresponding wall emissivity. However, it will be noted that for $\epsilon_{i}$ less than 0.4 , the total Nusselt numbers in case (A) are beneath that those of the case (B), this trend is reversed for large values of the emissivity $\left(\epsilon_{i}>0.4\right)$.

\section{Conclusion}

Interaction between natural convection and surface radiation in an inclined cavity with a wavy wall heated from below and filled with a transparent fluid has been studied. The effect of several parameters such as the amplitude undulation, surface radiation and aspect ratio for a selected range of Rayleigh number $\left(10^{3}-10^{7}\right)$ and tilt angle covered $\left(0^{\circ}-90^{\circ}\right)$ have been examined. The numerical results obtained in terms of Nusselt number, streamlines and isotherms were reported and led to the following conclusions:

- The flow structure and the heat transfer rate depend heavily on the undulation depth, inclination angle of the cavity, Rayleigh number and surface radiation.

- Independently of surface radiation, up to $R a=5 \times 10^{4}$, the conduction is the prevailing mode of heat transfer; beyond this value the convection becomes predominant. The flow remains steady state until $R a=10^{7}$ then an oscillatory flow is observed.

- It should be noted that for lower $R a$ number when diffusion is dominating, the convective heat transfer rate decreases with increasing the wavy wall amplitude. This tendency is reversed for largest $R a$ values where convection plays an important role. There, the convective heat transfer rate increases with increasing the amplitude of the wavy wall.

- The surface radiation has an important effect, especially in the range of the cold wall emissivity variation (0-0.4).

- The variation of the dimensionless amplitude (b) has a greater effect on the convective heat transfer rate in the range of tilt angle $\phi=30^{\circ}-45^{\circ}$.

- Heat transfer (convective and radiative) depends particularly on the emissivity walls of the cavity.

\section{References}

[1] G.D.V. Davis, Natural convection of air in a square cavity a bench mark numerical solution, Int. J. Numer. Methods Fluids 3 (1983) 249-264

[2] P. Le Quere, Accurate solutions to the square thermally driven cavity at high Rayleigh number, Comput. Fluids 20 (1991) 29

[3] L. Adjlout, O. Imine, A. Azzi, M. Belkadi, Laminar natural convection in an inclined cavity with a wavy wall. Int. J. Heat Mass Transfer 45 (2002) 2141-2152

[4] P.K. Das, S. Mahmud, Numerical investigation of natural convection inside a wavy enclosure, Int. J. Thermal Sci. 42 (2003) 397-406
[5] A. Dalal, M.K. Das, Laminar natural convection in an inclined complicated cavity with spatially variable wall temperature, Int. J. Heat Mass Transfer 48 (2005) 38333854

[6] W. Gao, W. Lin, T. Liu, C. Xia, Analytical and experimental studies on the thermal performance of crosscorrugated and flat-plate solar air heaters, Appl. Energy 84 (2007) 425-441

[7] Y. Varol, H.F. Oztop, Free convection in a shallow wavy enclosure, Int. Commun. Heat Mass Transfer 33 (2006) $764-771$

[8] Y. Varol, H.F. Oztop, A comparative numerical study on natural convection in inclined wavy and flat-plate solar collectors, Building and Environment 43 (2008) 15351544

[9] S. Saha, T. Sultana, G. Saha, M.M. Rahman, Effects of discrete isoflux heat source size and angle of inclination on natural convection heat transfer flow inside a sinusoidal corrugated enclosure, Int. Commun. Heat Mass Transfer 35 (2008) 1288-1296

[10] A. S. Bendehina, O. Imine, L. Adjlout, Laminar free convection in undulated cavity with non-uniform boundary conditions, C. R. Mecanique 339 (2011) 42-57

[11] C. Chen, C. Cheng, Predictions of buoyancy-induced flow in various across-shape concave enclosures, Int. Commun. Heat Mass Transfer 38 (2011) 442-448

[12] R. Nasrin, S. Parvin, M.A. Alim, Effect of Prandtl number on free convection in a solar collector filled with nanofluid, Proc. Eng. 56 (2013) 54-62

[13] M.M. Rahman, S. Mojumder, S. Saha, S. Mekhilef, R. Saidur, Augmentation of natural convection heat transfer in triangular shape solar collector by utilizing water based nanfluids having a corrugated bottom wall, Int. Commun. Heat Mass Transfer 50 (2014) 117-127

[14] A. Sahi, D. Sadaoui, B. Meziani, and K. Mansouri, Effects of thermal boundary conditions, surface radiation and aspect ratio on thermal performance in " $\mathrm{T}$ " shallow cavity, Mechanics \& Industry 15 (2014) 557-568

[15] G. Lauriat, Combined radiation-convection in gray fluids enclosed in vertical cavities, J. Heat Transfer 104 (1982) 609-615

[16] E. H. Ridouane, M. Hasnaoui, A. Amahmid, A. Raji, Interact between natural convection and radiation in a square cavity heated from below, Numer. Heat Transfer Part A 45 (2004) 289-311

[17] H. Wang, S. Xin, P. Le Quéré, Étude numérique du couplage de la convection naturelle avec le rayonnement de surfaces en cavité carrée remplie d'air, C. R. Acad. Sci. Mécanique 334 (2006) 48-57

[18] H. Bouali, A. Mezrhab, H. Amaoui, M. Bouzidi, Radiation-natural convection heat transfer in an inclined rectangular enclosure, Int. J. Thermal Sci. 45 (2006) 553566

[19] A. Mezrhab, M. Jami, M. Bouzidi, P. Lallemand, Analysis of radiation-natural convection in a divided enclosure using lattice Boltzmann method, Comp. Fluids 36 (2007) 423-434 
[20] S. Amraqui, A. Mezrhab, C. Abid, Computation of coupled surface radiation and natural convection in an inclined "T" form cavity, Energy Conversion Management 52 (2011) 1166-1174

[21] R. Alvarado, J. Xamán, J. Hinojosa, G. Álvarez, Interaction between natural convection and surface thermal radiation in tilted slender cavities, Int. J. Thermal Sci. 47 (2008) 355-368

[22] H. F. Nouanegue, A. Muftuoglu, E. Bilgen, Heat transfer by natural convection, conduction and radiation in an inclined square enclosure bounded with a solid wall, Int. J. Thermal Sci. 48 (2009) 871-880

[23] M. Ashish Gad, C. Balaji, Effect of surface radiation on $\mathrm{RBC}$ in cavities heated from below, Int. Commun. Heat Mass Transfer 37 (2010) 1459-1464
[24] V. Vivek, Anil Kumar Sharma, C. Balaji, Interaction effects between laminar natural convection and surface radiation in tilted square and shallow enclosures, Int. J. Thermal Sci. 60 (2012) 70-84

[25] H. C. Hottel, A.F. Saroffim, Radiative Heat Transfer, Mc Graw Hill, New York, 1967

[26] S. V. Patankar, Numerical Heat Transfer and Fluid Flow, Hemisphere Publishing, New York, 1980

[27] H. John, I.V. Lienhard, H. John, V. Lienhard, A Heat Transfer Textbook 3rd edition, Phlogiston Press, Cambridge, Massachusetts, USA, 2004 